\title{
Characterization on strength and toughness of welded joint for Q550 steel
}

\author{
JIANG QINGLEI, LI YAJIANG*，WANG JUAN and ZHANG LEI \\ Key Laboratory for Liquid-Solid Structural Evolution and Processing of Materials (Ministry of Education), \\ Shandong University, Jinan 250061, Shandong Province, People's Republic of China
}

MS received 15 August 2009; revised 18 November 2009

\begin{abstract}
Q550 high strength steel was welded using gas shielded arc welding and three different welding wires without pre- or post-heat treatments. The paper investigates the influence of welding wire on the microstructure, tensile strength and impact toughness of Q550 steel weld joints. Results showed that the microstructure of the weld metal of joints produced using ER50-6 wire was a mixture of acicular ferrite and grain boundary ferrite including pro-eutectoid ferrite and ferrite side plate. Acicular ferrite was mainly obtained in the weld metal of the joints produced using MK·G60-1 wire. Pro-eutectoid ferrite was present along the boundary of prior austenite. Crack initiation occurred easily at pro-eutectoid ferrite when the joint was subjected to tensile. Tensile strength and impact toughness were promoted with increasing acicular ferrite. Tensile strength of the joint fabricated using MK.G60-1 wire was close to that of base metal. And tensile samples fractured at location of the fusion zone, which had lower toughness and thus became the weak region in the joint. Impact absorbing energy was the highest in the heat affected zone. Fibrous region in fracture surfaces of impact specimens was characterized as transgranular fracture with the mechanism of micro-void coalescence. Acicular ferrite microstructure region corresponded to relatively large dimples while boundary ferrite microstructure corresponded to small dimples.
\end{abstract}

Keywords. Low alloy high strength steel; gas shielded arc welding; mechanical properties; microstructure.

\section{Introduction}

Low alloy high strength steels produced by thermomechanically controlled rolling (TMCP) are characterized by high strength, high toughness, formability, etc (Wang et al 2002; Lee et al 2007; Chang et al 2009). Due to reasonable economy and high allowable design stresses, they are widely used in the construction of engineering machinery, bridges, buildings, ships, pipeline, etc (Fukumoto 1996; Zhao et al 2002). TMCP technology makes it possible to obtain excellent combination of strength and toughness with the microstructure of low carbon bainite, by accelerated cooling immediately after controlled rolling process. Due to the rapid development of steel structures, fabrication costs and efficiency have become key factors for further development of low alloy high strength steel. Thus, it is expected to use TMCP thick steel plates in manufacturing industry as a substitute for traditional low alloy thick steel plates.

The welding of thick steel plates has been an important process in steel structures manufacturing. Weld thermal cycle associated with chemical compositions of welding wires is known to directly affect both the macro and microstructure of weld metal and the heat affected zone (HAZ) which in turn influences the mechanical properties of the welding joint.

*Author for correspondence (yajli@sdu.edu.cn)
Weld alloying is mainly used to increase the strength and toughness of the weld metal through adding suitable alloys to increase the content of acicular ferrite (AF) in the weld metal. In industrial production, welding technique having high efficiency and quality as well as low cost, labour intensity and energy consumption is found to be very important in the welding of steel structures. While welding technology without pre or post heat treatments is considered to be important in this direction (Spanos et al 2001; Dhua et al 2002).

High welding heat input is preferred in industries for saving welding time and increasing production efficiency. However, high heat input results in considerable variation in microstructure of weld metal and HAZ. The heat input used in the welding should be restricted to lower range. Because of slower cooling rate at higher heat input, microstructure of weld metal and HAZ changes, coarsening of prior austenite grain and precipitation of undesirable hard phases take place leading to the deterioration of tensile strength and impact toughness (Dixon and Hakansson 1995; Dhua et al 2002).

In the present study, attempts were made to weld $20 \mathrm{~mm}$ thick plates of Q550 steel using different alloy welding wires by $\mathrm{Ar}+\mathrm{CO}_{2}$ mixed gas shielded arc welding without pre or post heat treatments. The microstructure of weld metal as well as the mechanical properties including tensile strength and impact toughness of the welding joints were studied. Fractography of the impact specimens was carried out. And 


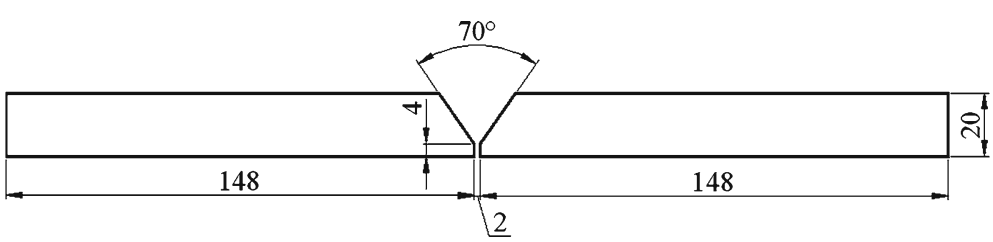

Figure 1. Groove geometry of test plates (all dimensions are in $\mathrm{mm}$ ).

characterization on tensile strength and impact toughness of the welded joint was analysed.

\section{Experimental}

The steel used in the test was Q550 steel, belonging to low alloy high strength steel, produced by TMCP technology. Low carbon bainite features were revealed in microstructure of the base metal. The test plates of $300 \times 148 \mathrm{~mm}$ and $20 \mathrm{~mm}$ thickness were prepared. Subsequently single ' $\mathrm{V}$ ' groove angles (35 degree) were cut in the plates with $4 \mathrm{~mm}$ root faces and $2 \mathrm{~mm}$ root distance for a total of 70 degree inclined angle between two plates. The geometry of the groove design is shown in figure 1. ER50-6, MK.G60 and MK. G60-1 welding wires ( $1.2 \mathrm{~mm}$ in diameter) were employed to fabricate the joints using $\mathrm{Ar}+\mathrm{CO}_{2}$ mixed gas shielded arc welding. Chemical compositions of Q550 steel and several welding wires are presented in table 1 and mechanical properties are provided in table 2 .

The welding tests were conducted using NBC-500 arc welding machine and were carried out by means of multilayer and multi-pass welding. The shielded gas was $80 \%$ $\mathrm{Ar}+20 \% \mathrm{CO}_{2}$ with a flow of $18-20 \mathrm{~L} / \mathrm{min}$. The welding parameters to fabricate the joint specimens were: welding current 260-320 A, arc voltage, 26-31 V, welding speed, $30-54 \mathrm{~cm} / \mathrm{min}$, as shown in table 3 .

The transverse through-thickness (T-T) sections of the weld joints were polished using standard metallographic procedure. The specimens were mechanically polished and etched with $5 \%$ Nital solution for observation of the microstructure using Nikon AFX-A optical microscope. The microstructure in the weld metal was analysed using ImagePro Plus image analysing software. Thin foils cut from weld metal were prepared for transmission electron microscopy
(TEM). The foils were examined in HITACHI H800 microscope at $150 \mathrm{kV}$ accelerating voltage. Energy dispersive spectrometry (EDS) of thin foils was conducted using a Link's EDS system.

For mechanical properties evaluation, the joints were sliced and then machined to the required dimensions for preparing tensile and impact specimens. A special care was taken to have the weld zone at the middle of the standard plate tensile test samples and the weld section was kept vertical to longitudinal axis of the specimen. The geometry of tensile sample is shown in figure $2 \mathrm{a}$. The samples were prepared and tested according to AWS B4.0 and ASTM E8M standards. The tensile testing was carried out in WAW-600 computer-controlled electro-hydraulic-servo universal testing machine at room temperature. Standard Charpy V-notch $(\mathrm{CVN})$ samples of $10 \times 10 \times 55 \mathrm{~mm}$ dimensions with $2 \mathrm{~mm}$ V-notch were prepared according to ASTM E 23 standard. The samples were cut in the transverse $\mathrm{T}-\mathrm{T}$ direction with the notch normal to the weld surface, keeping the position of the notch in the respective weld metal, fusion zone and HAZ locations as indicated in figure $2 b$. The CVN tests were conducted using 300J Charpy Impact Testing Machine at $0^{\circ}$. For both tensile and impact testing, three specimens were tested for each condition, and the average values were reported. Fractographic studies of the tested impact specimens were carried out via JEOL JXA-880R electron probe microanalysis (EPMA).

\section{Results and discussion}

\subsection{Microstructure}

The microstructure of base metal was fine low carbon bainite as shown in figure $3 \mathrm{a}$. The microstructure of weld metal produced using three different welding wires is shown in

Table 1. Chemical compositions and mechanical properties of tested steel and welding wires.

\begin{tabular}{|c|c|c|c|c|c|c|c|c|c|c|}
\hline \multirow{2}{*}{ Type of materials } & \multicolumn{10}{|c|}{ Chemical compositions (wt.\%) } \\
\hline & $\mathrm{C}$ & $\mathrm{Mn}$ & $\mathrm{Si}$ & $\mathrm{Nb}$ & $\mathrm{Cr}$ & $\mathrm{Ti}$ & Mo & $\mathrm{P}$ & $S$ & $\mathrm{Fe}$ \\
\hline Q550 (Base metal) & 0.079 & 1.763 & $0 \cdot 372$ & $0 \cdot 067$ & - & - & - & $0 \cdot 020$ & $0 \cdot 020$ & Balance \\
\hline ER50-6 & 0.08 & 1.41 & 0.83 & - & - & - & - & $0 \cdot 018$ & $0 \cdot 020$ & Balance \\
\hline MK·G60 & 0.09 & 1.79 & 0.73 & - & - & - & $0 \cdot 36$ & $0 \cdot 019$ & $0 \cdot 015$ & Balance \\
\hline MK·G60-1 & 0.09 & $1 \cdot 70$ & 0.65 & - & 0.09 & $0 \cdot 11$ & - & $0 \cdot 011$ & 0.017 & Balance \\
\hline
\end{tabular}


Table 2. Mechanical properties of tested steel and welding wires.

\begin{tabular}{lccrr}
\hline & \multicolumn{4}{c}{ Mechanical properties } \\
\cline { 2 - 5 } Type of materials & Yield strength, $\sigma_{\mathrm{s}}(\mathrm{MPa})$ & Tensile strength, $\sigma_{\mathrm{b}}(\mathrm{MPa})$ & Elongation, $\delta_{5}(\%)$ & Impact energy, $A_{\mathrm{kV}}(\mathrm{J})$ \\
\hline Q550 (Base metal) & 550 & 760 & $\geq 16$ & $\geq 40\left(-20^{\circ} \mathrm{C}\right)$ \\
ER50-6 & 459 & 561 & 24 & $84\left(-29^{\circ} \mathrm{C}\right)$ \\
MK·G60 & 575 & 635 & 25 & $90\left(-20^{\circ} \mathrm{C}\right)$ \\
MK·G60-1 & 600 & 665 & 23 & $60\left(-40^{\circ} \mathrm{C}\right)$ \\
\hline
\end{tabular}

Table 3. Welding parameters utilized in the preparation of the test samples.

\begin{tabular}{lcccccc}
\hline & & \multicolumn{3}{c}{ Welding parameters } \\
\cline { 3 - 7 } Welding method & Welding groove & $\begin{array}{c}\text { Welding current } \\
(\mathrm{A})\end{array}$ & $\begin{array}{c}\text { Welding voltage } \\
(\mathrm{V})\end{array}$ & $\begin{array}{c}\text { Welding speed } \\
\left(\mathrm{cm} \cdot \mathrm{min}^{-1}\right)\end{array}$ & $\begin{array}{c}\text { Shielding gas } \\
\left(\mathrm{L} \cdot \mathrm{min}^{-1}\right)\end{array}$ \\
\hline Gas shielded arc welding & V-type & $260-320$ & $26-31$ & $30-54$ & $80 \% \mathrm{Ar}+20 \% \mathrm{CO}_{2}$ & $18-20$ \\
\hline
\end{tabular}

figures $3 \mathrm{~b}-\mathrm{d}$, respectively. The weld metal microstructure of joint welded with ER50-6 wire mainly revealed acicular ferrite (AF) in interior of grain and grain boundary ferrite including pro-eutectoid ferrite $(\mathrm{PF})$ presenting along the boundary of prior austenite and ferrite side plate (FSP) from boundaries to interior as indicated in figure $3 \mathrm{~b}$. Analysis of the microstructure by means of Image-Pro Plus image analysing software showed that there is $\sim 65 \%$ AF. The weld metal (figure 3c) of joint produced with MK.G60 wire also exhibited PF and AF structure, and PF content decreased obviously with AF fraction of $\sim 78 \%$. The microstructure phases in weld metal of joint fabricated using MK·G60-1 wire consists of interpenetrating $\mathrm{AF}$, and a spot of PF and bainite as shown in figure $3 \mathrm{~d}$. The PF was suppressed when cooling resulting in $\sim 94 \%$ AF content.

The transmission electron microscopy of the weld metal produced using MK.G60-1 wire revealed AF and bainitic ferrite. The AF structure illustrated in figure 4 depicts high density dislocation tangle and pileup, and micro substructure. The fine effective grains size and high dislocation conditions of AF definitely make it difficult for slipping inside grains and deformation between adjacent grains.

The microstructure in weld metal is primarily determined by chemical composition. The formation and growth of AF are affected by addition of alloying elements and cooling rate after welding process. Some kinds of alloying elements increase the stability of austenite and block off the transformation of austenite into grain boundary ferrite including PF and FSP by reducing austenite-to-ferrite transformation temperature viz. $A_{\mathrm{r} 3}$ in literature. PF and FSP were suppressed which in turn increased the proportion of intermediate transformation structure including $\mathrm{AF}$ and bainite. According to previous workers (Babu 2004), AF is of thermal nonequilibrium structure and a kind of intragranular nucleation bainite. The difference between them is that bainite nucleates on prior austenite grain boundaries while AF nucleates on non-metallic inclusions inside the austenite grains. Slow cooling rate after welding accelerates transformation process of PF or FSP, while fast cooling rate may promote the formation of martensite. In order to obtain more AF content in the weld metal, the cooling rate should be controlled moderately by managing the welding heat input which is determined by welding current, welding voltage and welding speed.

Ti based inclusions such as $\mathrm{Ti}_{2} \mathrm{O}_{3}$ or $\mathrm{TiO}$ can be formed in the weld metal because of the origin of Ti from MK.G601 wire. These inclusions as heterogeneous nuclei assist in nucleation of AF in the weld metal structure which is desirable from the point of view of toughness (Yang et al 2006). They are thermally stable and even do not lose their ability in promoting the formation of AF structure at fusion zone. The inclusions also can accelerate the transformation of $\gamma \rightarrow \alpha$, which makes the transition temperature at grain boundaries and within the grains tend to be uniform. Thus, microstructure of AF forms easily to some extent.

\subsection{Tensile test and Charpy impact test}

The tensile strength of tensile samples extracted from joints of welded plates produced using ER50-6 and MK.G60-1 wires was $699.6 \mathrm{MPa}$ and 740.3 MPa, respectively as shown in table 4 . The latter had increased by $5.82 \%$ than the former and was close to that of base metal. The elongation of the two kinds of samples from welded joints was respectively $7.54 \%$ and $8.73 \%$. In the tests, fracture of the samples from joint produced using ER50-6 wire occurred at the weld metal, while that of MK·G60-1 wire occurred near the fusion zone.

There was relatively high proportion of PF structure present along the grain boundaries of prior austenite in the weld metal of the joints produced with ER50-6 wire compared to that of the joints produced using MK·G60-1 wire. When the joint was subjected to tensile force that exceeded 

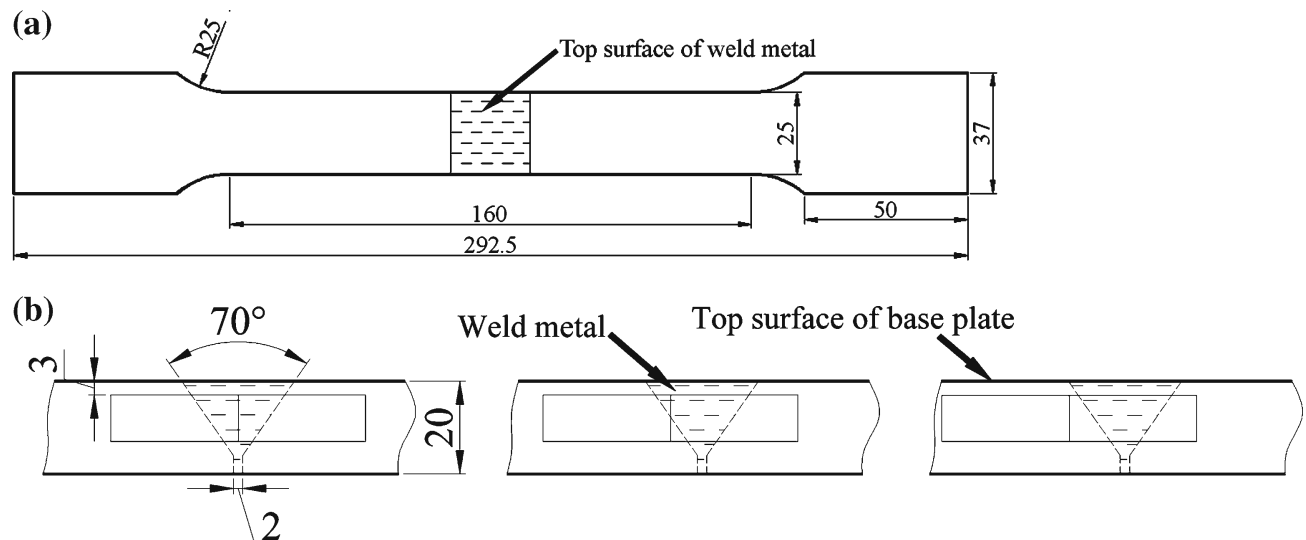

Figure 2. Schematic diagrams showing (a) geometry of tensile samples and (b) location and orientation of Charpy specimens in weld metal, fusion zone, and HAZ, respectively from left to right (all dimensions are in $\mathrm{mm}$ ).
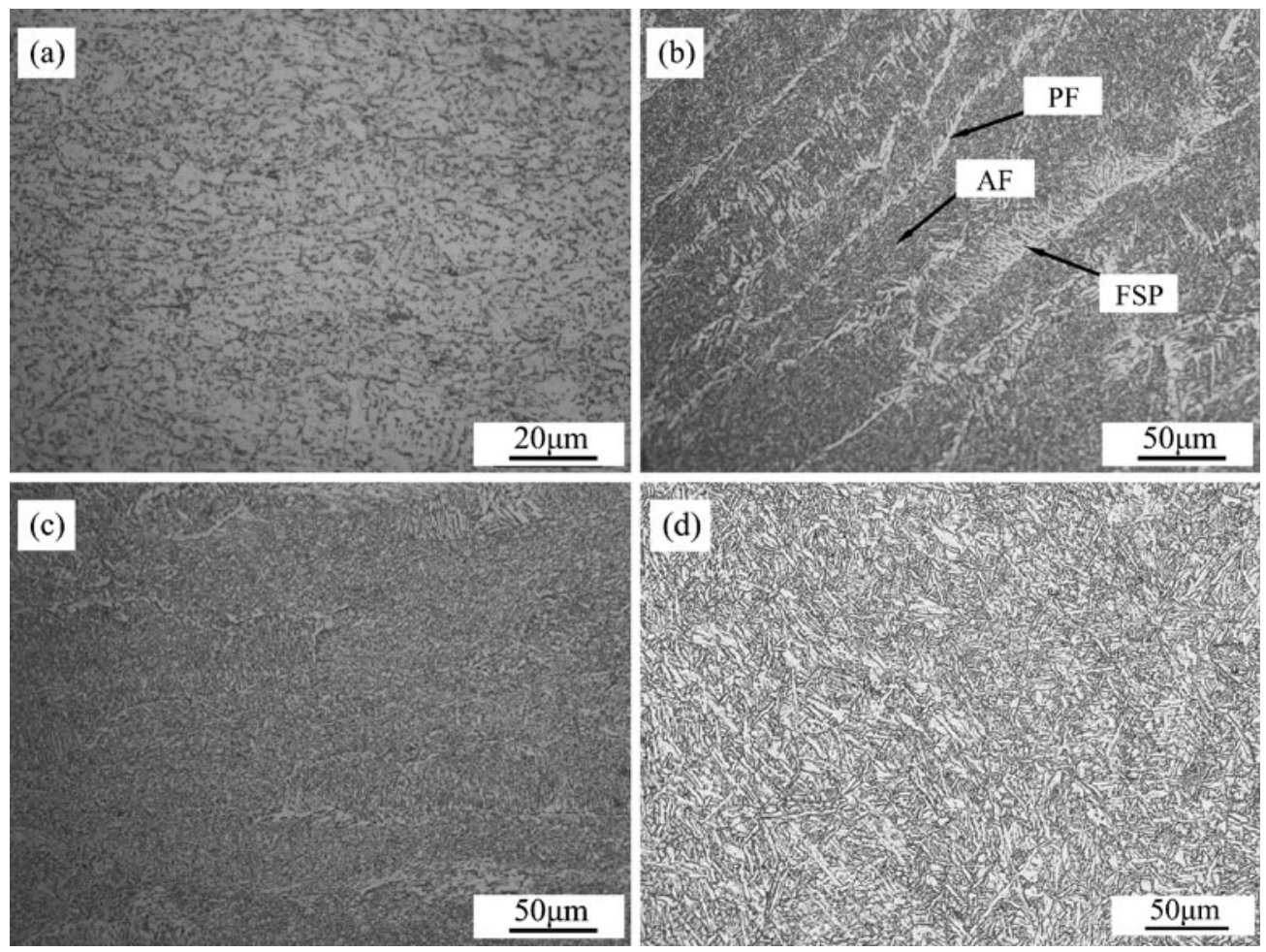

Figure 3. Optical microstructure of the weldment: (a) base metal depicting bainite, (b) microstructure of weld metal using ER50-6 wire, (c) weld metal microstructure using MK·G60 wire, and (d) microstructure of weld metal using MK·G60-1 wire.

plasticity reserve of the weld metal, plastic deformation occurred first at the grain boundaries. As the PF has poor ability of resisting the crack, crack initiation occurred easily at $\mathrm{PF}$ and propagated along the $\mathrm{PF}$ structure. AF structure with high dislocation enhanced the tensile strength of weld metal in the joints (Johnson et al 1995). Thus, the tensile strength in the joints produced using ER50-6 wire was lower than that of the joints using MK.G60-1 wire.
The Charpy V-notch (CVN) impact energies of the weld metal, fusion zone and $\mathrm{HAZ}$ at $0^{\circ} \mathrm{C}$ testing temperature for the samples from joints produced using ER50-6 and MK.G60-1 wires are given in table 5. Tests were carried out 3 times and the average value was considered. The variation of Charpy impact energies for the samples extracted from different sections of the joints are exhibited in figure 5. The CVN energies of the weld metal, fusion zone 

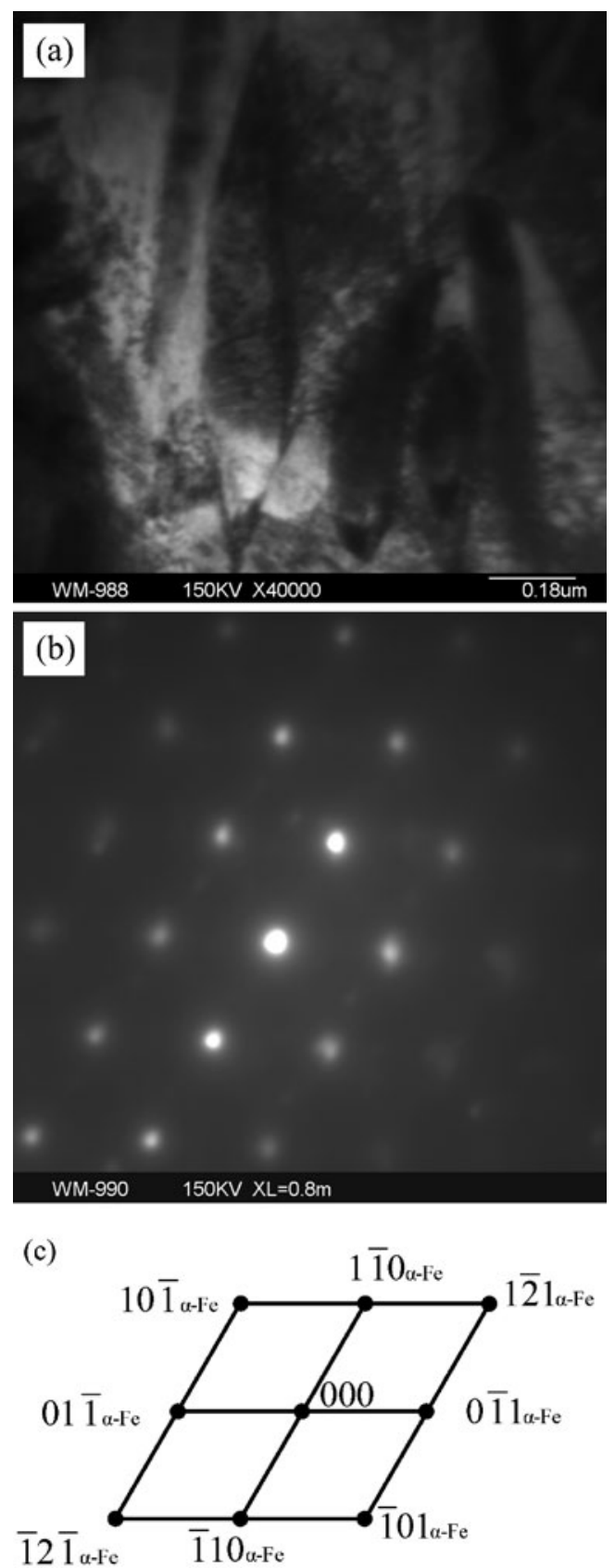

Figure 4. TEM of the weld metal produced using MK·G60-1 wire: (a) AF morphology, (b) corresponding electron diffraction pattern, and $(\mathbf{c})$ index diagram $(\mathrm{B}=[111])$.

and HAZ for samples produced using ER50-6 wire were $115 \mathrm{~J}, 96 \mathrm{~J}$ and $169 \mathrm{~J}$, and that for samples produced using MK·G60-1 wire were $127 \mathrm{~J}, 115 \mathrm{~J}$ and $162 \mathrm{~J}$. The results showed that for both kinds of joints, the HAZ had highest toughness as compared to weld metal and fusion zone, while the fusion zone had the lowest toughness. The CVN energy in weld metal produced using MK·G60-1 wire was higher by
Table 4. Experimental results of tensile strength for Q550 joints.

\begin{tabular}{lcccc}
\hline No. & Welding wire & $\begin{array}{c}\text { Tensile strength, } \\
\sigma_{\mathrm{b}}(\mathrm{MPa})\end{array}$ & $\begin{array}{c}\text { Elongation, } \\
\delta_{5}(\%)\end{array}$ & $\begin{array}{c}\text { Rupture } \\
\text { location }\end{array}$ \\
\hline 1 & ER50-6 & $699 \cdot 6$ & $7 \cdot 54$ & Weld metal \\
2 & MK.G60-1 & $740 \cdot 3$ & 8.73 & Fusion zone \\
\hline
\end{tabular}

Table 5. Experimental results of impact test for Q550 joints at $0^{\circ} \mathrm{C}$.

\begin{tabular}{lccc}
\hline No. & Welding wire & Notch location & Impact energy, $A_{\mathrm{kV}}(\mathrm{J})$ \\
\hline 1 & ER50-6 & Weld metal & 115 \\
2 & ER50-6 & Fusion zone & 96 \\
3 & ER50-6 & HAZ & 169 \\
4 & MK·G60-1 & Weld metal & 127 \\
5 & MK·G60-1 & Fusion zone & 115 \\
6 & MK·G60-1 & HAZ & 162 \\
\hline
\end{tabular}

$10.43 \%$ than that of weld metal produced using ER50-6 wire, and CVN energy in fusion zone was higher by $19.79 \%$.

The AF structure is considered to be very effective in enhancing the toughness in weld metal. High angle grain boundaries of AF prevent crack propagation. And the fine grains of AF influence greatly on the curvilinear path of crack propagation resulting in requirement of more energy. The increase in fraction of AF structure will promote the toughness of weld metal and fusion zone. So AF is interpreted as the optimal metallographic microstructure in the weld metal (Spanos et al 1995; Basu and Raman 2002). Because of the different conditions of melting crystallization and phase transformation between the two sides of fusion zone, the region with a sudden change in chemical compositions and microstructure properties formed around the fusion zone, where the structure was significantly heterogeneous. Thus, an inevitable result of a variety of micro-defects (such as vacancies, dislocations, etc) made the fusion zone as the weak region of performance in the joints.

\subsection{Fracture surface of Charpy specimens}

Fractographic studies of the impact specimens extracted from joints produced using ER50-6 and MK·G60-1 wires were carried out. Figure 6 shows typical fracture surfaces of the broken Charpy specimens tested with notches located at weld metal. Figures $6 \mathrm{a}$ and $\mathrm{b}$ exhibit, respectively the fibrous zone and radical zone in fracture surface of specimen produced using ER50-6 wire. And figures $6 \mathrm{c}$ and d illustrate the fibrous zone and radical zone in fracture surface, respectively of specimen fabricated with MK·G60-1 wire. 


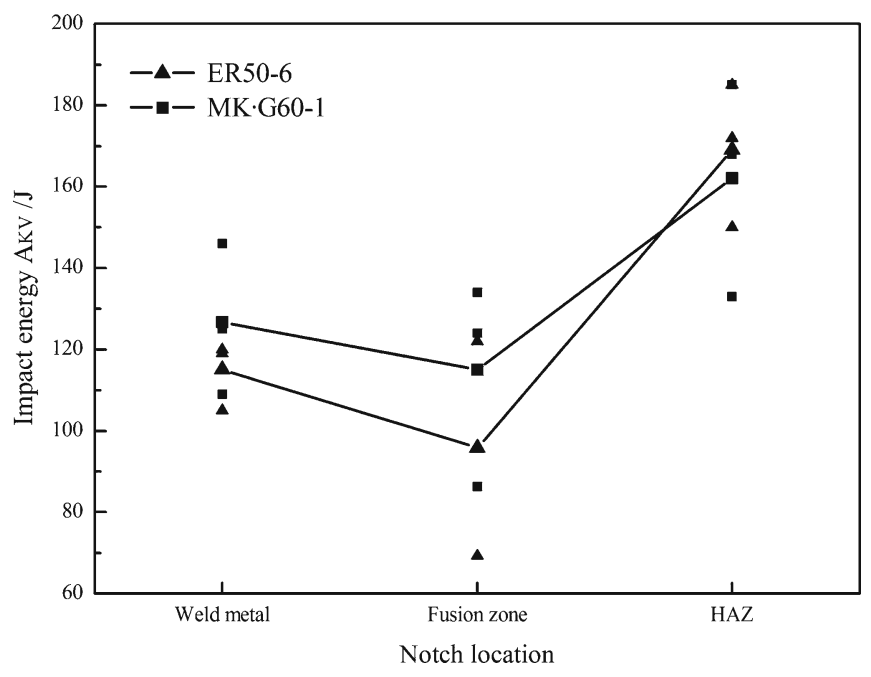

Figure 5. Impact absorbing energy in weld metal, fusion zone and HAZ of samples from Q550 steel joints.

Figures $6 \mathrm{a}$ and $\mathrm{c}$ show dense globular or elliptic dimples in the fracture surface confirming ductile character of failures. Figure $6 \mathrm{c}$ reveals coarser dimples compared to figure 6a, which are in accordance with their microstructure and CVN energies. In the fracture surface of weld metal from ER50-6 joint, less amount of large dimples zone were surrounded by small dimples zone as indicated in figure 6 a Spherical particles with small dimensions could be observed at the bottom of some dimples. They might consist of one or several kind of oxides, sulfides, carbonitrides, etc which were formed in the welding process. In case of the fibrous zone of weld metal from the joint produced using MK.G601 , there were mostly large and coarse dimples. And a few of small dimples only could be found among the large ones. There were also micro-voids on the dimples. On comparing microstructure with fracture surfaces, region with AF structure corresponded to relatively large dimples and ferrite at the boundary of grain corresponded to small dimples. It was evident from figures $6 \mathrm{a}$ and $\mathrm{c}$ that increasing of AF can elevate the amount of large dimples on the fractured surface. Fibrous zone in fractured surfaces of impact test specimens was characterized as transgranular fracture with the mechanism of micro-void coalescence. The different sizes of dimples were primarily attributed to the properties of AF and PF. The cracks propagated quickly in the PF region presenting along the grain boundaries. Low energies were necessary for small dimples. AF had higher resistance to crack growth as mentioned above. As a result, the plastic deformation was large for AF structure leading to large dimples as shown in figure $6 \mathrm{c}$.

In the radical zone of fracture surface, the crack propagated more quickly than that in the fibrous zone. It was
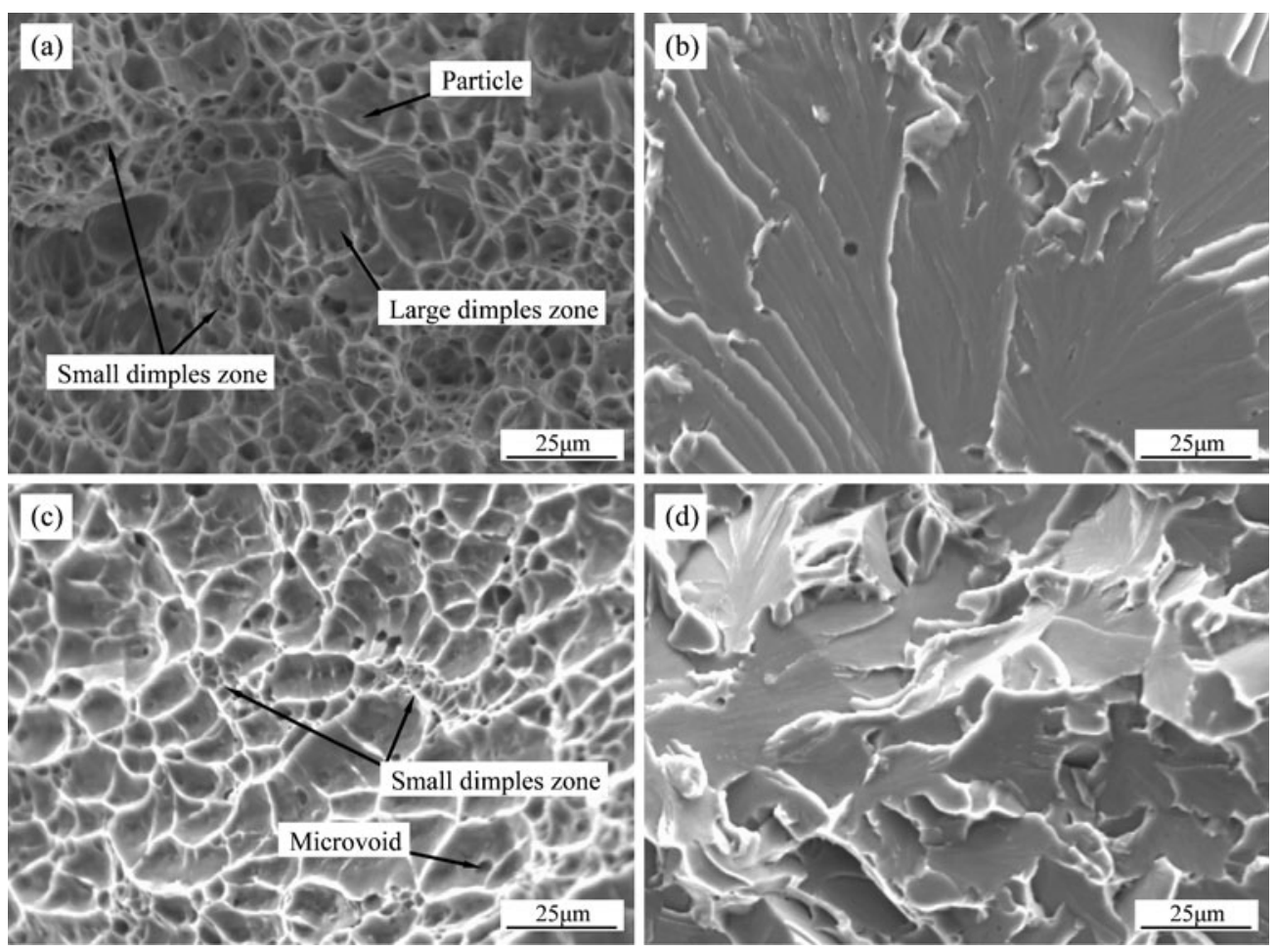

Figure 6. Fractographs of the Charpy impact specimens tested at $0^{\circ} \mathrm{C}$ : (a) the fibrous zone, (b) radical zone from joint produced using ER50-6 wire, (c) the fibrous zone and (d) radical zone from joint produced using MK·G60-1 wire. 
shown in figure $6 \mathrm{~b}$ that fractured surface of the weld metal from ER50-6 joint was flat with radiating river patterns. The cleavage planes were smooth with radiating cleavage steps.

Figure $6 \mathrm{~d}$ shows the radical zone of the fractured surface of weld metal produced using MK·G60-1 wire, which exhibits rough cleavage planes with cleavage steps, a spot of river patterns and white tearing ridge. The fractured surface indicates good resistance to crack propagation and the tortuous crack propagation path. The fractured surface fluctuates obviously through macroscopic observation. The fractographic studies revealed that fine grains size of $\mathrm{AF}$ is effective in preventing the crack propagation, while fracture channel is easy to propagate along PF structure.

\section{Conclusions}

(I) Weld metal was the weak region of the joints produced using ER50-6 wire. Pro-eutectoid ferrite (PF) was presented along the grain boundary of prior austenite. Crack initiation occurred easily at PF when the joint was subjected to tensile. Acicular ferrite (AF) was mainly obtained in the weld metal of joints produced using MK·G60-1 wire. Tensile samples fractured at the location of fusion zone. The tensile strength of MK.G60-1 joints was close to that of base metal.

(II) Impact absorbing energy was highest in heat affected zone (HAZ) and lowest in the fusion zone. The impact toughness of weld metal and fusion zone of the joints fabricated using MK·G60-1 wire increased obviously compared to the joints produced using ER50-6 wire.

(III) Fibrous zone in fractured surfaces of impact specimens was characterized as transgranular fracture with the mechanism of micro-void coalescence. The region with AF corresponded to relatively large dimples while ferrite at the bound- ary of grain corresponded to small dimples. Radical region in the fractured surface of weld metal from ER50-6 joint was flat with river patterns. The fractured surface of weld metal produced using MK·G60-1 wire exhibited tortuous crack propagation path and rough cleavage planes.

\section{Acknowledgements}

This project is supported by the Development Project of Science and Technology of Shandong Province (2007GG10004016) and the Shandong Province Natural Science Foundation (Y2007F54). The authors express their heartfelt thanks here.

\section{References}

Babu S S 2004 Curr. Opin. Solid State Mater. Sci. 8267

Basu B and Raman R 2002 Weld. J. 81 239s

Chang K H, Jang G C, Park C M and Gil H B 2009 Comput. Mater. Sci. 45667

Dhua S K, Mukerjee D and Sarma D S 2002 ISIJ Int. 42290

Dixon B and Hakansson K 1995 Weld. J. 74 122s

Fukumoto Y 1996 Eng. Struct. 18786

Johnson M Q, Evans G M and Edwards G R 1995 ISIJ Int. 351222

Lee C H, Park H C, Jang G C, Lee J H and Chang K H 2007 Key Eng. Mater. 353-358 527

Spanos G, Fonda R W, Vandermeer R A and Matuszeski A 1995 Metall. Mater. Trans. A26 3277

Spanos G, Moon D W, Fonda R W, Menon E S K and Fox A G 2001 Metall. Mater. Trans. A32 3043

Wang S H, Luu W C, Ho K F and Wu J K 2002 Mater. Chem. Phys. 77447

Yang J, Wu L H and Mao J F 2006 Trans. China Weld. Inst. 2786

Zhao M C, Yang K and Shan Y Y 2002 Mater. Sci. Eng. A335 14 